\section{Death from pulmonary microembolisation after intravenous injection of temazepam}

Dr E J Vella (Pathology Laboratory, Lakin Road, Warwick CV34 5BJ) and Dr C W EDwards (Department of Pathology, East Birmingham Hospital, Birmingham B9 5ST) write: A 31 year old female drug misuser presented with pain in her right leg. She told the casualty doctor that a few hours previously she had crushed a few $10 \mathrm{mg}$ tablets of temazepam, dissolved them in water, and injected the solution intravenously into her right groin. No abnormality was found on examination. She was given paracetamol for the pain and sent home, where she died about 38 hours later.

At necropsy there was no arterial or venous thrombosis in the leg. Histologically, small pulmonary vessels contained basophilic fibrillary foreign material, which was also present in small vessels in the right groin. Postmortem blood samples showed temazepam $(286 \mu \mathrm{g} / \mathrm{l})$ and methadone $(120 \mu \mathrm{g} / \mathrm{l})$, plus traces of diazepam, desmethyldiazepam, and a breakdown product of chlormethiazole. These results showed no evidence of drug overdose, and death was attributed to pulmonary microembolisation of material injected intravenously into the right groin.

The severe morbidity associated with intra-arterial injection of temazepam has been well described,' but the dangers of intravenous injection are not well recognised. The present case appears to be the first recorded death associated with intravenous temazepam injection, and the pulmonary microemboli have not to our knowledge been described.

The nature of the foreign material in the small vessels of the lungs and groin is uncertain. It might represent contaminants introduced during crude filtration by the abuser before injection; cigarette filters are often used for this purpose (J Drake, per-

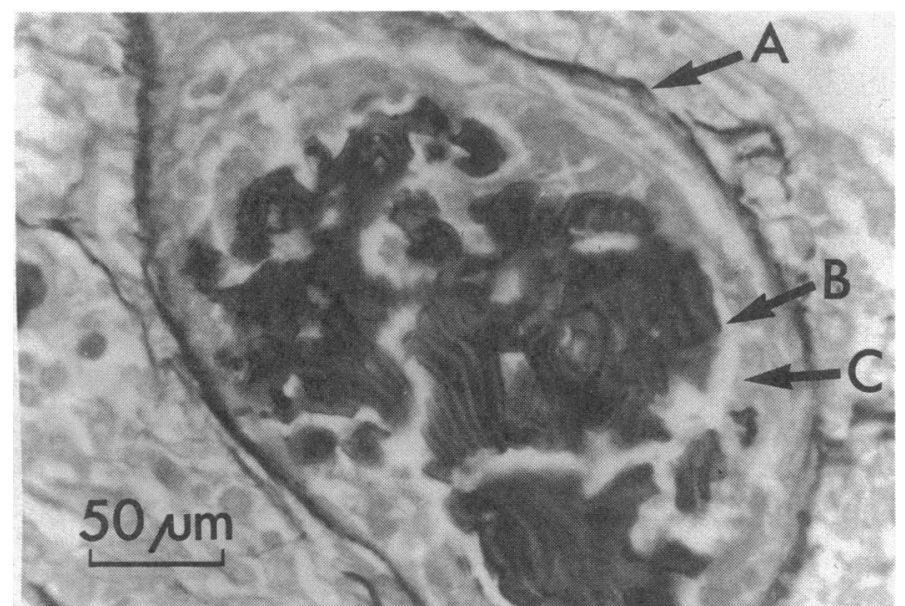

Section of lung showing small pulmonary vessel (A) containing embolised, fibrillary foreign material (B) and blood (C). Elastic van Gieson sonal communication). If so, this material could be responsible for the lysis which have been described after intra-arterial injection of temazepam gel. ${ }^{2}$ Other possibilities include excipients of temazepam tablets such as crospovidone, which is a hygroscopic, plastic like material commonly used to carry water insoluble drugs.

It has been suggested that temazepam tablets are less "abusable" than the capsules and should be prescribed in preference. ${ }^{34}$ This case shows that determined abusers of temazepam will devise methods of injecting the tablets, and that this can lead to death

We thank Amanda Fellows, drug Warwickshire Hospital, for providformulations.

1 Scott RN, Going J, Woodburn KR, Gilmour DG, Reid DB, Leiberman DP, et al. Intraarterial temazepam. BMF 1992;304: 1630.

2 Adiseshiah M, Jones DA, Round JM. Intraarterial temazepam. $B M \mathcal{F}$ 1992;304:1630.

Garvey T. Misuse of temazepam. BMJ 1992;305:253.

Innes CF, Cotter JC, Davies P, Wood NL Misuse of temazepam. BMF 1992;305:832.

\section{Josamycin-induced pedal oedema}

Drs X Bosch, E Pedrol, X Casado, and A Urbano-Marquez (Dispensari d'Urgències, Hospital Clínic Barcelona 08036, Spain) write: Josamycin is a macrolide antibiotic used increasingly for treating upper and lower respiratory tract infections. It differs from erythromycin in its greater tolerability, safety, and stability to gastric $\mathrm{pH} .^{1-4}$ Side effects are rare, and mainly include gastrointestinal complaints and hypersensitivity skin reactions. ${ }^{47}$. We report a case of pedal oedema related to josamycin.

A 56 year old man presented with a five-day history of high fever, accompanied by a non-productive cough and diarrhoea. His history was unrevascular blockages and rhabdomyoinformation pharmacist at South ing information about temazepam markable and he was taking no drugs. Apart from a temperature of $39.7^{\circ} \mathrm{C}$, examination was normal. Investigations revealed leucocytosis $\left(17 \times 10^{9} / 1\right)$ with a normal differential count and hyponatraemia (126 mmol//), while chest radiography showed alveolar shadowing of the left lower lobe. A sputum smear showed a few leucocytes and a negative Gram's stain. Non-pyogenic pneumonia was diagnosed and treatment started with josamycin $1 \mathrm{~g}$ twice daily. After three days in bed the fever had disappeared, but a bilateral non-pitting pedal oedema had developed. There was no rash and the serum sodium had returned to normal ( $137 \mathrm{mmol} / \mathrm{l})$. Josamycin was then replaced with erythromycin $500 \mathrm{mg}$ four times daily. After two days the oedema had disappeared, but the patient started complaining of increasing nausea and vomiting. Erythromycin was stopped and josamycin restarted. Within two days pedal oedema had redeveloped, slowly disappearing when josamycin was finally discontinued.

The temporal association strongly suggests that josamycin was responsible for the development of pedal oedema in this patient. Peripheral oedema has been reported as an adverse reaction to several drugs, chiefly non-steroidal anti-inflammatory drugs, calcium antagonists, and nitrates, ${ }^{7}$ although others are known. The exact mechanism of fluid retention in such cases is unclear. As far as we are aware, there are no published reports of peripheral oedema as a side effect of antibiotics, including the macrolide agents. We have no pathophysiological explanation for oedema formation during treatment with josamycin.

1 Westerman E, Williams T, Moreland N. In vitro activity of josamycin against aerobic gram-positive cocci and anaerobes. Antimicrob Agents Chemother 1976;9:988-93.

2 Strausbaugh L, Kline W, Dilworth J, Guerran $\mathrm{R}$, Sande M. Comparative pharmacology of josamycin and erythromycin stearate. Antimicrob Agents Chemother 1976;10:450-6.

3 Wenzel R, Hendley J, Dodd W, Gwaltney J. Comparison of josamycin and erythromycin in the therapy of Mycoplasma pneumoniae pneumonia. Antimicrob Agents Chemother 1976;10:899-901.

4 Privitera G, Bonino S, Del Mastro S. Clinical multicentre trial with josamycin propionate in paediatric patients. Int $\mathcal{F}$ Clin Pharm Res 1984;4:201-7.

5 Quinn X, Pilot M, Thompson H, Maskell J. Comparison of the side-effects and gastrointestinal motility observed after administration of erythromycin and josamycin to dogs. 7 Antimicrob Chemother 1986;18:747-56.

6 Mensa J, Trilla A, Tarrero I, Vidal J, Estruch R, Martinez JA, et al. Tratamiento de la neumonia atipica con josamicina. Med Clin (Barc) 1989;92:285-7.

7 Dukes MNG, ed. Meyler's Side Effects of Drugs. Amsterdam: Elsevier, 1988

Taste disorders and terbinafine

M Beutler, K HartmanN, and Drs $M$ KunN and J Gartmann (Swiss Drug Monitoring Center, Chur, Switzerland) write: During May to November 1992 we received six reports of taste disorders during treatment with terbinafine, ${ }^{1}$ a new antifungal drug of the allylamine type. We describe three of the cases.

Case 1-A 42 year old man taking no other drugs received terbinafine $250 \mathrm{mg}$ daily for onychomycosis in March 1992. Eight weeks after starting the treatment he developed hypogeusia. His taste had deteriorated to such an extent that he could no longer judge the quality of wine and barely sense the taste of food. After stopping treatment his condition persisted unchanged for two weeks and improved to norma within another two weeks.

Case 2-A 28 year old woman taking no other drugs began treatment with terbinafine $250 \mathrm{mg}$ daily for onychomycosis in March 1992. Two months later she developed a metallic taste in her mouth which subsequently progressed to ageusia. Her taste returned to normal six weeks after stopping the drug.

Case 3-A 57 year old woman began a course of terbinafine $250 \mathrm{mg}$ daily for onychomycosis in July 1992. She experienced disturbances of taste and smell five weeks late which resolved five weeks after stopping treatment. She had been taking triamcinolone since 1963 and an oestrogen containing preparation since 1991. According to the reporting physician the patient did not suffer from sinusitis.

Taste disorders are known to be related to some thiol containing compounds-for example, penicillamine, captopril, and thiouracil derivatives-but also to agents without sulphydryl groups-for example, enalapril, metronidazole, and certain antiproliferative drugs. ${ }^{2}$ The reason for the special propensity of these compounds to impair taste has not been established. Zinc deficiency caused by metal binding thio compounds was assumed to be responsible for taste alterations in testimonial reports, but confirmation is lacking. ${ }^{34}$

The fact that all six of the reported cases showed a similar time course and similar reversible symptoms, and that all occurred within eigh months of terbinafine's launch in Switzerland, suggest that taste disturbances may be a side effect of terbinafine treatment. This has to be expected occasionally and could affect patients' compliance. The manufacturer of terbinafine now estimates the incidence of taste disorders to be 1 in 800 (personal communication).

Balfour JA, Faulds D. Terbinafine. Drugs 1992;43:259-84.

Schiffman SS. Taste and smell in disease. N Engl F Med 1983;308:1275-9.

3 Jaffe IA. Adverse effects profile of sulfhydryl compounds in man. $A m$ f Med 1986;80: 471-6.

4 Abu-Hamdan DK, Desai H, Sondheimer J Felicetta J, Mahajan S, McDonald F. Taste acuity and zinc metabolism in captopriltreated hypertensive male patients. Am $\mathcal{f}$ Hypertens 1988;1:303-8S. 